\title{
Microstructure, Strength, and Fracture Topography Relations in AISI 316L Stainless Steel, as Seen through a Fractal Approach and the Hall-Petch Law
}

\author{
Oswaldo Antonio Hilders, ${ }^{1}$ Naddord Zambrano, ${ }^{2}$ and Ramón Caballero ${ }^{3}$ \\ ${ }^{1}$ Department of Physical Metallurgy, School of Metallurgical Engineering and Materials Science, Central University of Venezuela, \\ Apartado 47514, Los Chaguaramos, Caracas 1041-A, Distrito Capital, Venezuela \\ ${ }^{2}$ Foundation for Professional Development, The Venezuelan College of Engineering, Caracas 1050, Venezuela \\ ${ }^{3}$ Failure Analysis Laboratory, School of Metallurgical Engineering and Materials Science, Central University of Venezuela, \\ Apartado 47514, Los Chaguaramos, Caracas 1041-A, Distrito Capital, Venezuela
}

Correspondence should be addressed to Oswaldo Antonio Hilders; ohilders@hotmail.com

Received 8 May 2015; Accepted 1 July 2015

Academic Editor: Carlos Garcia-Mateo

Copyright (C) 2015 Oswaldo Antonio Hilders et al. This is an open access article distributed under the Creative Commons Attribution License, which permits unrestricted use, distribution, and reproduction in any medium, provided the original work is properly cited.

\begin{abstract}
The influence of the fracture surface fractal dimension $D_{F}$ and the fractal dimension of grain microstructure $D_{M}$ on the strength of AISI 316L type austenitic stainless steel through the Hall-Petch relation has been studied. The change in complexity experimented by the net of grains, as measured by $D_{M}$, is translated into the respective fracture surface irregularity through $D_{F}$, in such a way that the higher the grain size (lower $D_{M}$ values) the lower the fracture surface roughness (lower values of $D_{F}$ ) and the shallower the dimples on the fractured surfaces. The material was heat-treated at $904,1010,1095$, and $1194^{\circ} \mathrm{C}$, in order to develop equiaxed grain microstructures and then fractured by tension at room temperature. The fracture surfaces were analyzed with a scanning electron microscope, $D_{F}$ was determined using the slit-island method, and the values of $D_{M}$ were taken from the literature. The relation between grain size, $D_{M}$, mechanical properties, and $D_{F}$, developed for AISI 316L steel, could be generalized and therefore applied to most of the common micrograined metal alloys currently used in many key engineering areas.
\end{abstract}

\section{Introduction}

Many steels and conventional metallic alloys in general still fill an important place in engineering technology. Although nanocrystalline materials show promise for applications in several fields [1-4], their use is generally restricted for largescale applications [3]. On the other hand, many important engineering applications of materials involve the use of conventional metallic alloys in polycrystalline form. For these alloys, the individual grains generally ranged between 10 and $300 \mu \mathrm{m}$. Conventional metallic alloys are widely used in several engineering areas in which they will be difficult to replace in the near future. The knowledge related with microscopic grained metallic alloys is constantly updated. Some examples of these alloys can be seen in the recent literature [5-13].
In metallic polycrystalline alloys, the relation between the fracture surface features and the underlying microstructure is very well known [14-16]. As the mechanical properties depend on the microstructure, it is clear that the topography of the fractured surfaces is also related to the mechanical properties. On the other hand, in view of the usefulness of the fractal geometry to study the relation between fracture surface tortuosity and mechanical properties [17-27] and that of the Hall-Petch relationship to relate microstructure and mechanical properties [28-32], it is understandable that the microstructure-fracture topography-mechanical properties relationship can be studied by combining both approaches. So far only a few bridges have been built between these two approaches (see, e.g., $[28,33]$ ). The aim of this work is to establish a quantitative correlation between the fracture surface fractal dimension $D_{F}$ (a measure of tortuosity 
of a fracture surface) and the fractal dimension of grain microstructure $D_{M}$ (a measure of complexity of the internal net of grains) in AISI 316L type steel, as both can be related through the Hall-Petch law. The link between $D_{M}$ and $D_{F}$ can provide an understanding of the role of microstructure on the mechanics of crack propagation. This link arises because microstructure has a major influence on the topography of the fracture surface. The correlation between $D_{F}$ and $D_{M}$ could be a useful tool to analyze the connection among microstructure, design, fabrication, and performance, in both conventional [28-32] and nanocrystalline metallic alloys [1,2, $4,34,35]$.

\section{Materials and Methods}

The material used in this work was austenitic type AISI 316L stainless steel fabricated into hot-rolled bar with diameter of $25.4 \mathrm{~mm}$ provided by a commercial supplier. The chemical composition of the steel is $16.9 \mathrm{Cr}, 12.0 \mathrm{Ni}, 2.52 \mathrm{Mo}, 1.5 \mathrm{Mn}$, $0.35 \mathrm{Si}, 0.025 \mathrm{C}, 0.035 \mathrm{~N}, 0.030 \mathrm{P}$, and $0.030 \mathrm{~S}$ (wt.\%). Four slices and eight tensile samples of $25.4 \mathrm{~mm}$ gage length were taken from the as-received bar and heat-treated at four different temperatures: $904,1010,1095$, and $1194^{\circ} \mathrm{C}$, in order to develop equiaxed grain microstructures (one slice and two tensile samples for each temperature). The temperatures were selected according to the work of Colás [36]. After the heat treatments, the slices and tensile samples were waterquenched at room temperature. Then, the slices were ground and polished by standard metallographic methods, while the microstructure was revealed by electrolytic etching.

An automatic image analyzer was used in order to perform grain size measurements according to the mean linear intercept method. At least ten different fields of view were analyzed for each metallographic sample. Before performing the measurements of grain size, the grain boundaries were extracted and enhanced by means of image processing techniques [37]. Briefly, well-defined grain boundaries were obtained transforming our 256 gray level images to two gray values: black and white (thresholding). Then, a specialized operation that prevents the separation of grain boundaries while eroding away pixels is performed (skeletonization). Finally, an image processing was done to eliminate impurities, particles, and so forth in the grain interiors (hole filling).

The tensile samples were deformed at room temperature at a nominal strain rate of $3.5 \times 10^{-4} / \mathrm{s}$ in an Instron tensile machine until fracture. A $10 \mathrm{~mm}$ section from both the cup and the cone portions of fractured tension samples was removed and the fracture surfaces were analyzed with a scanning electron microscope (SEM), which was operated at $20 \mathrm{Kv}$. The fractographic features were studied in the central region of the cup portion of broken samples using several micrographs for each case.

The values of the fracture surface fractal dimension $D_{F}$ have been determined using the so-called slit-island method (SIM) $[17,19,24,38-41]$ in the central region of the respective cone portions. Each cone was cold molding using epoxy resin, which was pouring over the sample (which was previously attached to a cylindrical support of convenient size). Each
TABLE 1: Average grain size and $D_{F}$ data.

\begin{tabular}{lcccc}
\hline$T\left({ }^{\circ} \mathrm{C}\right)$ & 904 & 1010 & 1095 & 1194 \\
$d(\mu \mathrm{m})$ & $21.4 \pm 3.1$ & $27.2 \pm 3.3$ & $67.9 \pm 4.9$ & $148.8 \pm 7.8$ \\
$D_{F}$ & 1.281 & 1.260 & 1.225 & 1.142 \\
\hline
\end{tabular}

sample was positioned face up, allowing the epoxy to cover all the fracture surface. Grinding and polishing operations were performed parallel to the mean plane of fracture, developing a number of successive layers in which part of the fracture surface becomes visible ("islands"). As the layers increased in number, the islands do, and growth and coalescence of islands take place. For a particular $j$ th layer with $n$ islands, $P i$ and $A i$ represent the perimeter and the area of the $i$ th island, respectively. Taking into account all the islands in this layer, the total perimeter and the total area are $\Sigma P i$ and $\Sigma A i$, respectively. For all the layers, a full logarithmic scale diagram of $\Sigma P i$ versus $\Sigma A i$ leads to obtaining a straight curve, from which $D_{F}=2 \times$ slope. Figure 1 shows an example of a sequence of 4 nonconsecutive partial layers (out of 26), to calculate the value of $D_{F}=1.142$.

On the other hand, the values of the microstructural fractal dimension were taken from the work of Colás [36]. In order to estimate the values of $D_{M}$, Colás employed the box-counting method [42]. In this method, a square grid containing boxes of a given side length $h$ is superimposed on the grain boundary pattern. Then, the number of boxes $N(h)$ containing boundary contours is counted. This process is repeated to find $N(h)$ for smaller values of $h$. Asymptotically, in the limit of small $h$,

$$
N(h)=N_{o} h^{-D_{M}},
$$

where $N_{o}$ is a constant. For a fractal pattern, the slope of the straight curve $\log N(h)$ versus $\log h$ is the microstructural fractal dimension $D_{M}$ whose values are between 1.0 and 2.0.

\section{Results and Discussion}

\subsection{The Relation between Yield Stress and $D_{F}$}

3.1.1. Grain Size- $D_{F}$ Relationship. Figure 2 shows optical micrographs of the microstructures of AISI 316L steel heattreated at four different temperatures. Figure 3 shows the enhanced microstructures of AISI 316L steel after the image processing.

The data of fracture surface fractal dimension $D_{F}$ and average grain size $d$ are listed in Table 1. On the other hand, Figure 4 shows the fracture surface fractal dimension $D_{F}$ plotted against the average grain size $d$. As can be seen, there is a negative linear correlation between $D_{F}$ and $d$, that is, higher fracture surface fractal dimension for lower average grain size. The corresponding equation is

$$
D_{F}=\lambda-\beta d,
$$

where $\lambda=1.30$ and $\beta=0.001 / \mu \mathrm{m}$. Equation (2) represents the connection between the microstructure (grain size) and the irregularity of the fracture surface (measured by $D_{F}$ ). The 


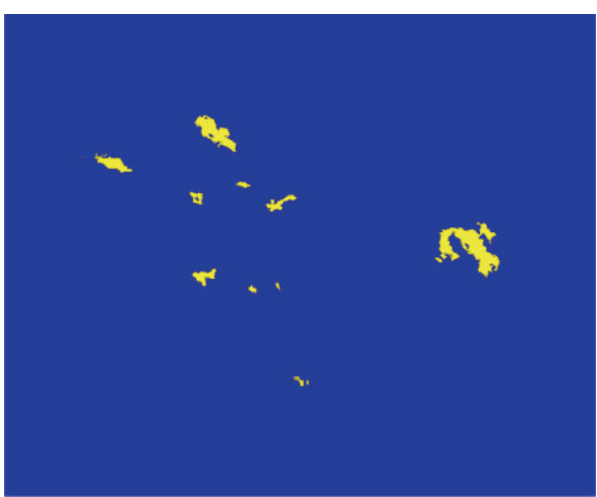

(a)

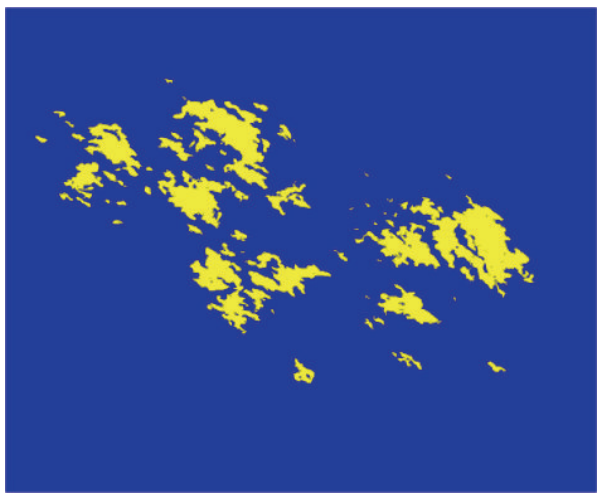

(c)

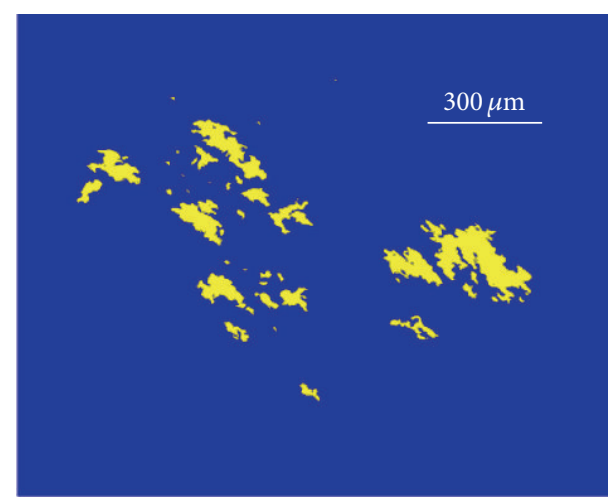

(b)

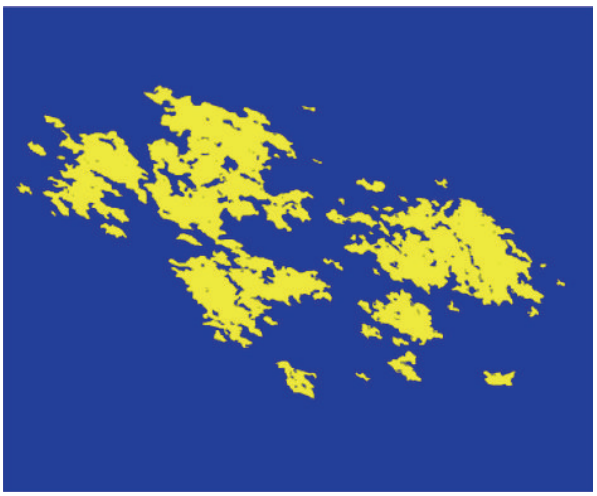

(d)

FIGURE 1: Optical micrographs of metallic islands of AISI 316L stainless steel, developed according to the SIM. (a) Layer number 1, (b) layer number 7, (c) layer number 14, and (d) layer number 24.

results predicted in Figure 4 are consistent with the general observation that grain size reduction is a means to increase the toughness of a metallic alloy [43,44], since, as many studies have been strongly supported, the higher the fracture surface fractal dimension is, the higher the toughness is [19, $21,39,45-47]$.

3.1.2. Fracture Surface Characteristics. Figure 5 shows several fractographs of the fractured tensile samples, which correspond to the four heat treatment temperatures. The microvoid coalescence mechanism of separation was observed for all experimental conditions. Although the values of $D_{F}$ increase as the grain size decreases according to Figure 4, the corresponding values of dimple size (as seen on the mean plane of fracture in Figure 5) were somewhat the same, which implies, in principle, that the dimple size (as measured by the surface dimple diameter) is not related with the grain size. In view of this fact, some factor must exist for the decrease in $D_{F}$ as the grain size increases.

As $D_{F}$ is a measure of the irregularity of the fracture surface, it is suggested that the dimples become shallow as the grain size increases (lower values of $D_{F}$ ) which was confirmed by in situ extensive analysis (SEM). This can be checked in Figure 5, at least for the extreme values of grain size developed in the present work: Figure 5(a): lower grain size ("deep dimples") and Figure 5(d): higher grain size ("shallow dimples").
The last view is supported by the fact that for smaller grain size the plastic deformation spreads out to the microstructure more easily than for larger grain size (smaller grain material stores more energy than larger grain material), creating a rougher fracture surface ("deep dimples") with a higher fractal dimension $D_{F}$. The rougher the fracture surface, the higher the stored energy and the tougher the material. Obviously, for this case the internal area of the "deep dimples" is also higher. Note that for a totally brittle material (which is not the case in any of the studied conditions) the absorbed energy is zero, and the fracture surface is flat.

Currently, a relationship between grain size and the deep of dimples in ductile fracture can be established indirectly, through the toughness. Note that, for a tougher material tested in tension, the plasticity is higher and the dimples are more enlarged in the axial direction ("deep dimples"). Figure 6 can illustrate these concepts.

On the other hand, the reason for dimples to remain about the same diameter is that dimple size is controlled by the size and population of particles (precipitates and/or inclusions) in the interior of grains $[48,49]$. After the nucleation of dimples begins from particles, their size increases until the coalescence with other dimples, which inhibits an additional growth. Provided the density and size of particles were the same for all experimental conditions, the corresponding average dimple size becomes roughly the same. 


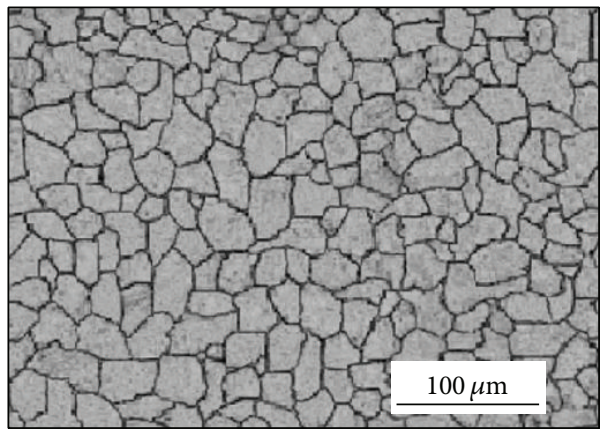

(a)

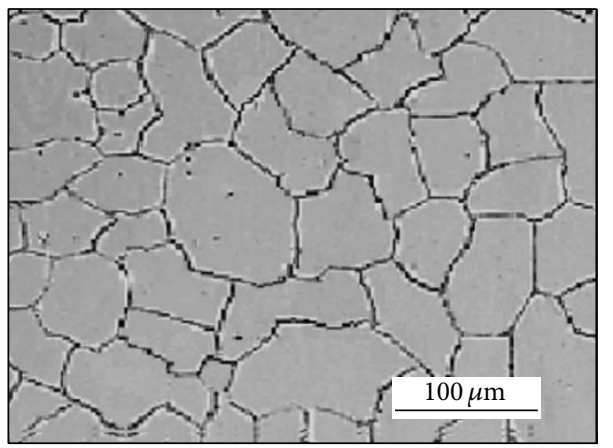

(c)

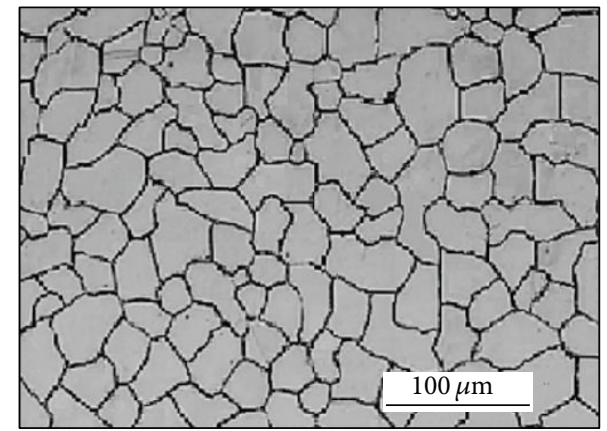

(b)

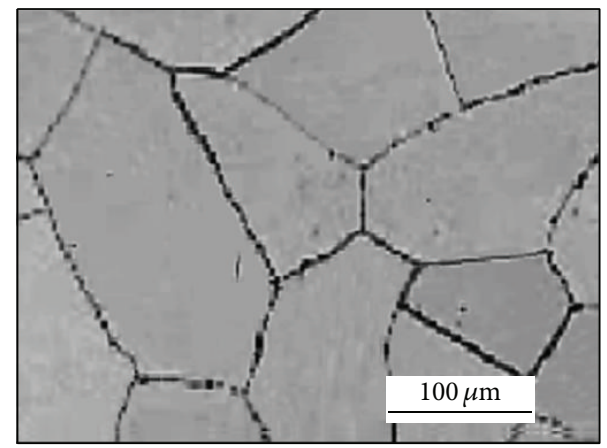

(d)

Figure 2: Optical micrographs of microstructures of AISI $316 \mathrm{~L}$ austenitic stainless steel heat-treated at (a) $904^{\circ} \mathrm{C}$, (b) $1010^{\circ} \mathrm{C}$, (c) $1095^{\circ} \mathrm{C}$, and (d) $1194^{\circ} \mathrm{C}$.

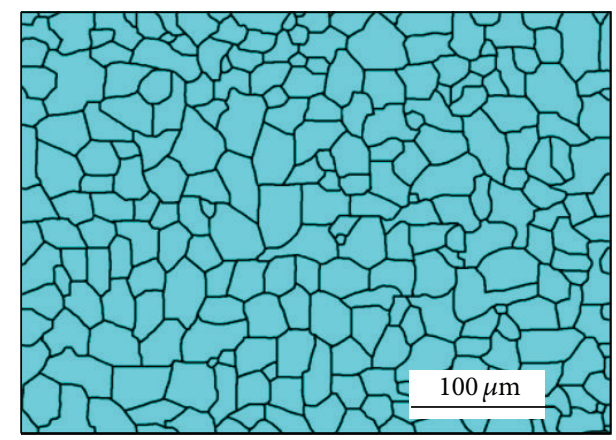

(a)

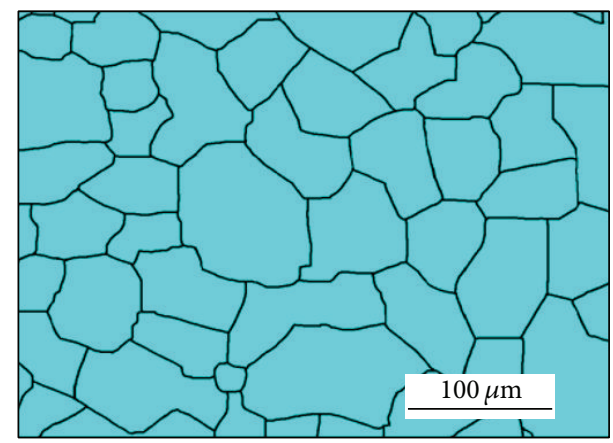

(c)

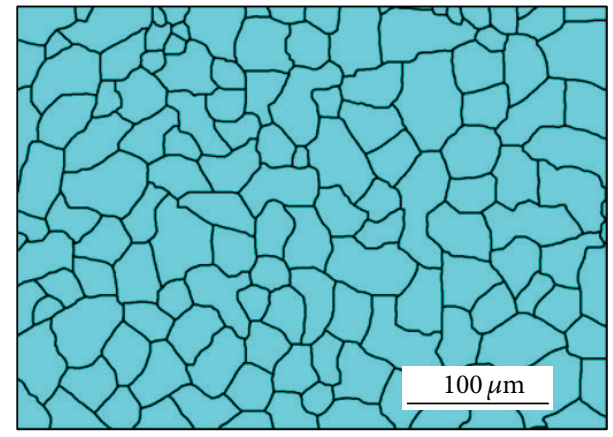

(b)

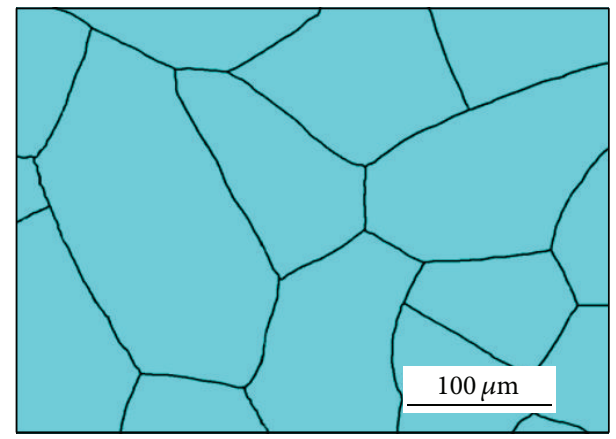

(d)

FIGURE 3: The processed images of grain microstructures of AISI 316L austenitic stainless steel corresponding to the micrographs of Figure 2. 


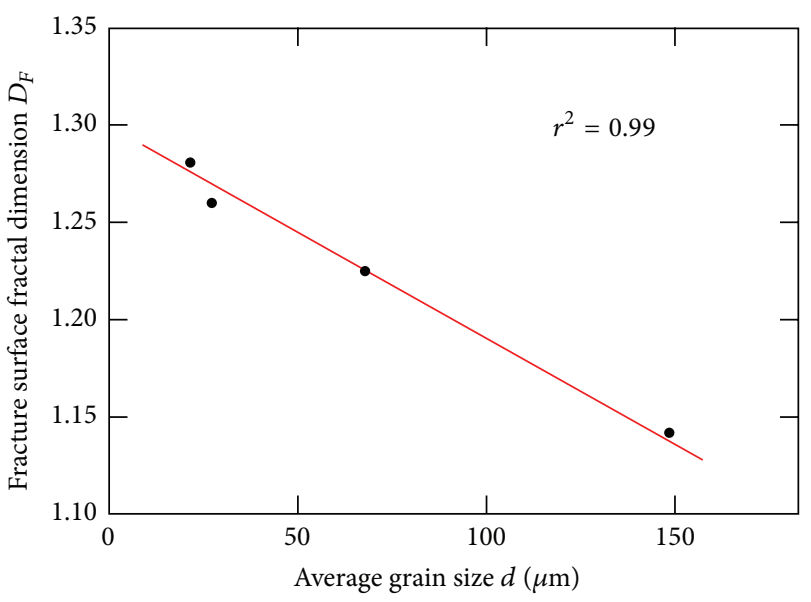

Figure 4: Variation of the fracture surface fractal dimension with the average grain size for AISI $316 \mathrm{~L}$ austenitic stainless steel.

The relative absence of particles inside the dimples in Figure 5 could be related with one or more of several factors: some particles remain attached to the matting fracture surface, some particles were lost during the fracture event, or simply some voids (few of them) nucleate homogeneously. Note that the relation between grain size and $D_{F}$ is easier to explain for the case of intergranular fracture (which was not obtained in any case in the present work). For intergranular separation, as the path of the fracture surface follows the contour of grains, a lower grain size material will have a higher area of grains and correspondingly a higher area of the fracture surface. In this case, the value of $D_{F}$ will be higher too.

3.1.3. Hall-Petch Type Relation for $D_{F}$. The relation between the fracture surface fractal dimension and mechanical properties has been established through the Hall-Petch equation:

$$
\sigma_{y}=\sigma_{o}+k d^{-1 / 2},
$$

where $\sigma_{y}$ is the yield stress, $\sigma_{o}$ is the friction stress which opposes dislocation motion, $k$ is a constant related with the difficulty in spreading yielding from grain to grain, and $d$ is the average grain size. From (2) the average grain size is $d=\left(\lambda-D_{F}\right) / \beta$, and then (3) is therefore rearranged to predict the yield stress as

$$
\sigma_{y}=\sigma_{o}+k^{\prime}\left(\lambda-D_{F}\right)^{-1 / 2},
$$

where $k^{\prime}=k \beta^{1 / 2}$ is a constant. For AISI 316L $\sigma_{o}=163 \mathrm{MPa}$ and $k=0.77 \mathrm{MPa} \mathrm{m}^{1 / 2}$ [50], $k^{\prime}$ becomes $24.35 \mathrm{MPa}$. Then, smaller grain size corresponds to higher fracture surface fractal dimension and so to higher yield stress. Based on (4), two Hall-Petch type relations have been represented in Figure 7: a linear relation of $\sigma_{y}$ versus $\left(\lambda-D_{F}\right)^{-1 / 2},(\lambda=1.30)$, and $\sigma_{y}$ versus $D_{F}$. In the first case, the theoretical values corresponding to $\left(\lambda-D_{F}\right)^{-1 / 2}$ ranged between $1.83\left(D_{F}=1\right)$ and $\infty\left(D_{F}=1.30\right)$, being the values of $\sigma_{y}, 207.46 \mathrm{MPa}$, and $\infty$, respectively.
TABle 2: Average grain size and $D_{M}$ data [36].

\begin{tabular}{lcccc}
\hline$T\left({ }^{\circ} \mathrm{C}\right)$ & 904 & 1010 & 1095 & 1194 \\
$d(\mu \mathrm{m})$ & $19.6 \pm 3.6$ & $29.6 \pm 4.8$ & $59.3 \pm 5.2$ & $158.4 \pm 8.2$ \\
$D_{M}$ & 1.504 & 1.470 & 1.423 & 1.365 \\
\hline
\end{tabular}

The value of $\sigma_{y}=207.46 \mathrm{MPa}$ represents the yield stress for AISI 316L steel broken in tension, whose fracture surface is totally flat $\left(D_{F}=1\right)$. Theoretically, for this case the value of $d$ should be $300 \mu \mathrm{m}$, (see (2)). For the curve $\sigma_{y}$ versus $D_{F}$ in Figure 7, the limit conditions are the same, although the approach to $\sigma_{y}=\infty$ as $D_{F} \rightarrow 1.30$ is of a nonlinear nature. The general Hall-Petch type relationship between $\sigma_{y}$ and $D_{F}$ (see (4)) can be potentially useful to relate the fracture surface fractal dimension $D_{F}$ with mechanical properties in many commercial alloys.

\subsection{The Relation between Yield Stress and $D_{M}$}

3.2.1. Grain Size- $D_{M}$ Relationship. According to Colás [36], the relationship between the average grain size $d$ and its microstructural fractal dimension $D_{M}$ for AISI $316 \mathrm{~L}$ can be described by means of the following equation:

$$
D_{M}=\alpha d^{-\eta},
$$

where $\alpha=1.716 \mu \mathrm{m}^{\eta}$ and $\eta=0.045$. This equation predicts an increase in $D_{M}$ as the grain size decreases. The data of microstructural fractal dimension and the range of the investigated average grain size upon which (5) was developed are listed in Table 2 [36].

3.2.2. Hall-Petch Type Relation for $D_{M}$. According to (5), the average grain size is $d=\left(\alpha / D_{M}\right)^{1 / \eta}$. This microstructural fractal dimension dependence for $d$ is substituted into (3), to predict the yield stress as a function of $D_{M}$ according to

$$
\sigma_{y}=\sigma_{o}+k^{\prime \prime} D_{M}^{1 /(2 \eta)}
$$

where $k^{\prime \prime}=k / \alpha^{1 /(2 \eta)}$ is a new constant. From the values of $k, \alpha$, and $\eta, k^{\prime \prime}=1.91 \mathrm{MPa}$. It can be seen that the yield stress increases as the microstructural fractal dimension increases, which in turn means a decrease in the average grain size. For the present case, and based on (6), once again two Hall-Petch type relations can be plotted (Figure 8): a linear relation $\sigma_{y}$ versus $\left(D_{M}\right)^{1 /(2 \eta)},(\eta=0.045)$, and $\sigma_{y}$ versus $D_{M}$. Three subscales for the variable $\left(D_{M}\right)^{1 /(2 \eta)}$ have been used in Figure 8 in order to preserve a natural arithmetic scale, which facilitates a good visualization of the fractal dimension values. This is performed according to the "level" of $D_{M}$. The first zone is defined for $1.0 \leq\left(D_{M}\right)^{1 /(2 \eta)} \leq 10,\left(1.0 \leq D_{M} \leq 1.23\right)$, so from (6) two values of $\sigma_{y}$ can be defined, $\sigma_{y}=164.91 \mathrm{MPa}$, $\left(\left(D_{M}\right)^{1 /(2 \eta)}=1, D_{M}=1\right)$ and $\sigma_{y}=182.1 \mathrm{MPa},\left(\left(D_{M}\right)^{1 /(2 \eta)}=\right.$ $\left.10, D_{M}=1.23\right)$; thus, the curve for this zone can be traced. It is suggested that the first zone could be identified with low complex microstructures. The second zone ranged between $\left(D_{M}\right)^{1 /(2 \eta)}=10$ and some value around 100. The last limit can 


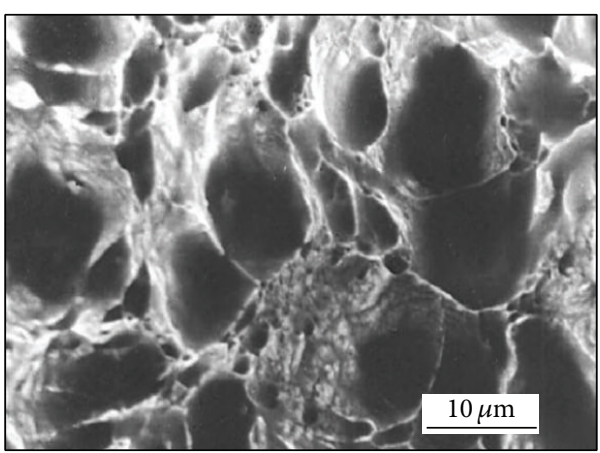

(a)

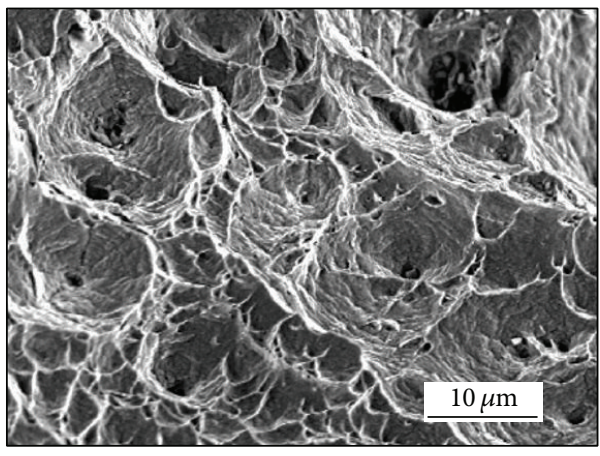

(c)

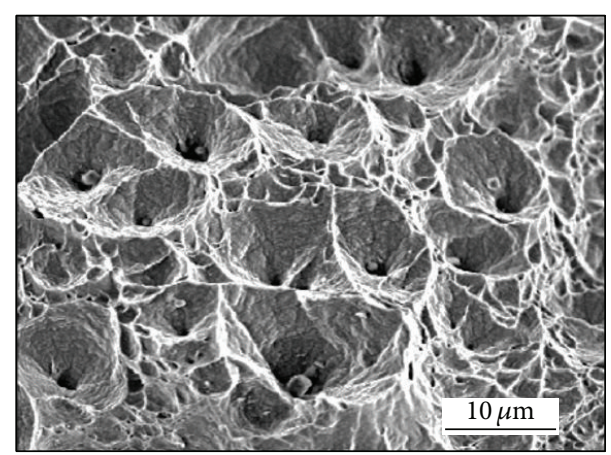

(b)

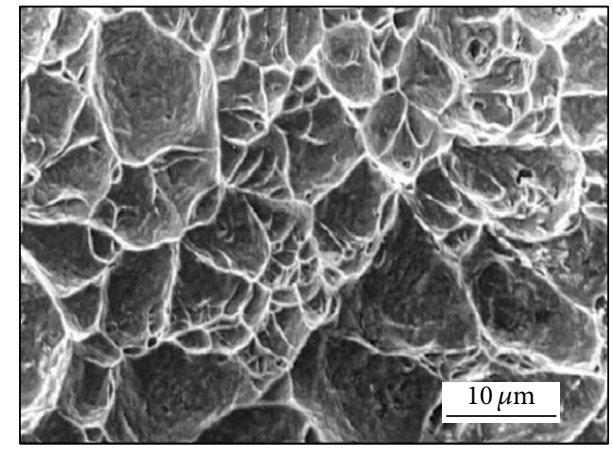

(d)

FiguRE 5: Scanning electron fractographs of fractured tensile samples heat-treated at four different temperatures: (a) $904^{\circ} \mathrm{C}: d=21.4 \mu \mathrm{m}$, $D_{F}=1.281$; (b) $1010^{\circ} \mathrm{C}: d=27.2 \mu \mathrm{m}, D_{F}=1.260$; (c) $1095^{\circ} \mathrm{C}: d=67.9 \mu \mathrm{m}, D_{F}=1.225$; (d) $1194^{\circ} \mathrm{C}: d=148.8 \mu \mathrm{m}, D_{F}=1.142$.

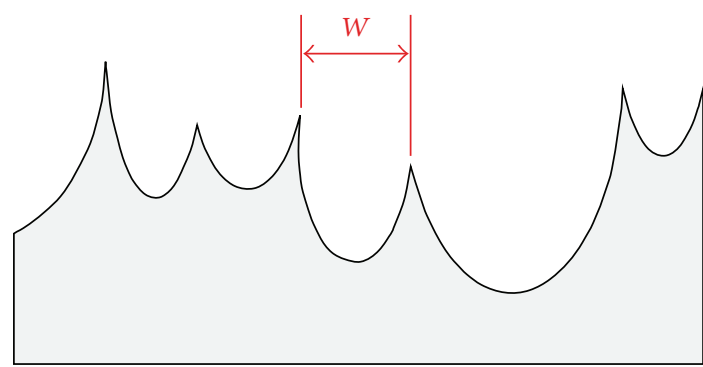

(a)

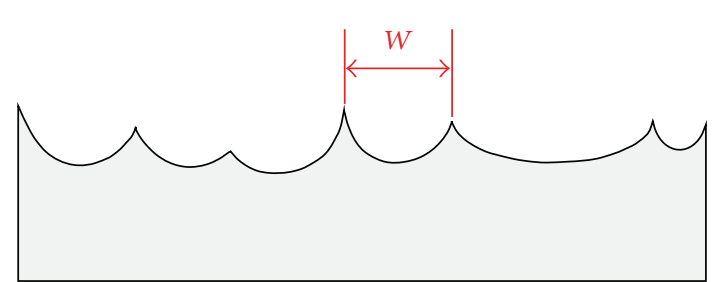

(b)

FIGURE 6: Ductile tension fracture surface profiles, showing the same average dimple size $W$ (axial direction is $\uparrow$ ). (a) “Deep dimples" for smaller grain size, in a tougher material with a higher $D_{F}$. (b) "Shallow dimples" for a higher grain size, in a material with smaller toughness and lower $D_{F}$.

move more or less freely in a narrow range, since it represents an uncertainty of the value for $\left(D_{M}\right)^{1 /(2 \eta)}$ (and therefore, the value of $D_{M}$ ) from which the related microstructure starts to be very complex in the third zone. For $\left(D_{M}\right)^{1 /(2 \eta)}=100$, $D_{M}=1.51$, so for the second zone, $1.23 \leq D_{M} \leq 1.51$. The second zone can represent microstructures with an average complexity. The curve for this zone can be traced using (6) for any two values of the corresponding scale. The curve for the third zone can be defined using one more time (6) and any two values of the third scale, for example, $\left(D_{M}\right)^{1 /(2 \eta)}=2,212$ $\left(D_{M}=2\right)$, which corresponds to $\sigma_{y}=4,387.84 \mathrm{MPa}$, and $\left(D_{M}\right)^{1 /(2 \eta)}=2,000\left(D_{M}=1.98\right)$, for $\sigma_{y}=3,983 \mathrm{MPa}$.
The value of $\sigma_{y}=164.91 \mathrm{MPa}$ represents the yield stress for AISI 316L steel broken in tension, for a grain size of $\approx 162,740.33 \mu \mathrm{m} \approx 16 \mathrm{~cm}$ (see (5)). We can write, as a first approximation (see (6)), that for $D_{M}=1, \sigma_{y} \approx \sigma_{o}=$ $163 \mathrm{MPa}$. Correspondingly, we could consider the material as an individual grain of $16 \mathrm{~cm}$ (an infinite system as compared to our real grains), which is consistent with the notion of $\sigma_{o}$ as a friction stress below which dislocations will not move in the material in the absence of grain boundaries. For $D_{M}=2, d=$ $0.03 \mu \mathrm{m}$ (see (5)) and $\sigma_{y}=4,387.84 \mathrm{MPa}$. From a theoretical point of view (see (6)), this microstructure can be related to such a high value of $\sigma_{y}$. Truly, a loss of strengthening for 


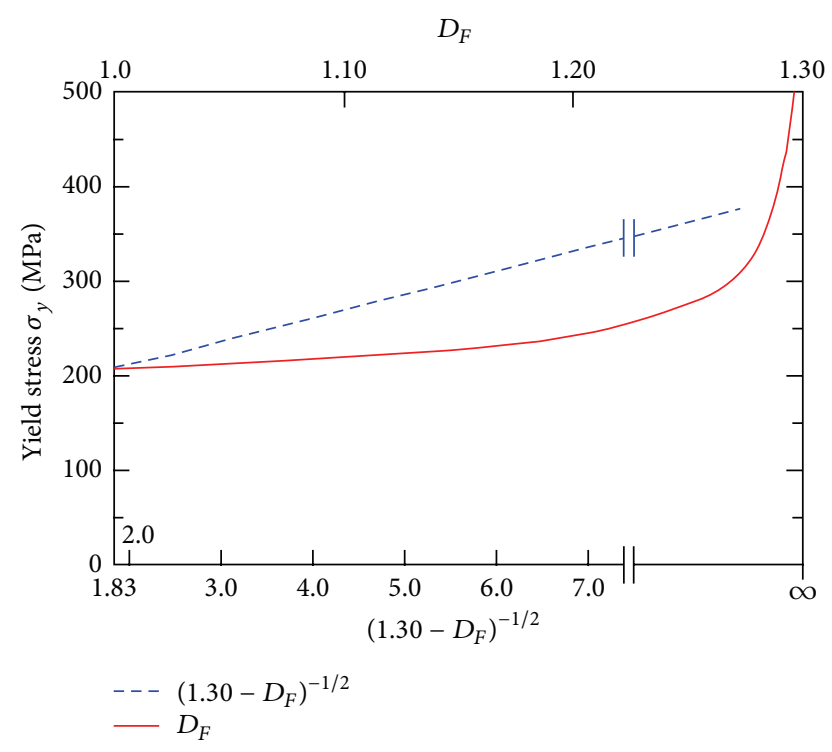

FIGURE 7: Hall-Petch type relations between yield stress and fracture surface fractal dimension for AISI 316L austenitic stainless steel.

$d=0.03 \mu \mathrm{m}(30 \mathrm{~nm})$ which falls into the so-called "inverse Hall-Petch dependence zone" $[51,52]$ should occur. For the curve $\sigma_{y}$ versus $D_{M}$ in Figure 8, two arithmetic subscales have been introduced which encompass the full theoretical range of $D_{M}\left(1 \leq D_{M} \leq 2\right)$. The natural link between the fractal dimension of grain boundaries and mechanical properties has been proven to be very important in metallic materials engineering [53-55]. On the other hand, the Hall-Petch type relationship between $\sigma_{y}$ and $D_{M}$ (see (6)) facilitates the comprehension of this link.

3.3. Relation between $D_{F}$ and $D_{M}$. The relation between the fracture surface fractal dimension $D_{F}$ and the microstructural fractal dimension $D_{M}$ can be found by equating (2) and (5), which leads to

$$
D_{F}=\lambda-\beta(\alpha)^{1 / \eta}\left(D_{M}\right)^{-1 / \eta}
$$

which in turn, taking into account the values of the constants $\alpha, \beta, \eta$ and $\lambda$, gives

$$
D_{F}=1.30-162.74\left(D_{M}\right)^{-22.22},
$$

where $22.22 \approx 1 / 0.045$ and 162.74 is a constant without dimensions. The relation between $D_{F}$ and $D_{M}$ is represented in Figure 9 and compared with $D_{F}=D_{M}$. As can be seen, the values of $D_{F}$ are smaller than the values of $D_{M}$, being the limit values: $D_{M}=1.328$ for $D_{F}=1$ and $D_{M}=2$ for $D_{F}=1.30$. The experimental values for $D_{M}$ and $D_{F}$ ranged between the intervals $1.365 \leq D_{M} \leq 1.504$ and $1.142 \leq D_{F} \leq 1.281$ as have been quoted in Tables 1 and 2, respectively.

The very nature of the relationship between $D_{M}$ and $D_{F}$ possesses great difficulties in analysis. Nevertheless, the present results confirm that an increase in $D_{M}$ or $D_{F}$ involves an increase in the yield stress as the grain size becomes small. Although both the box counting method [42], which

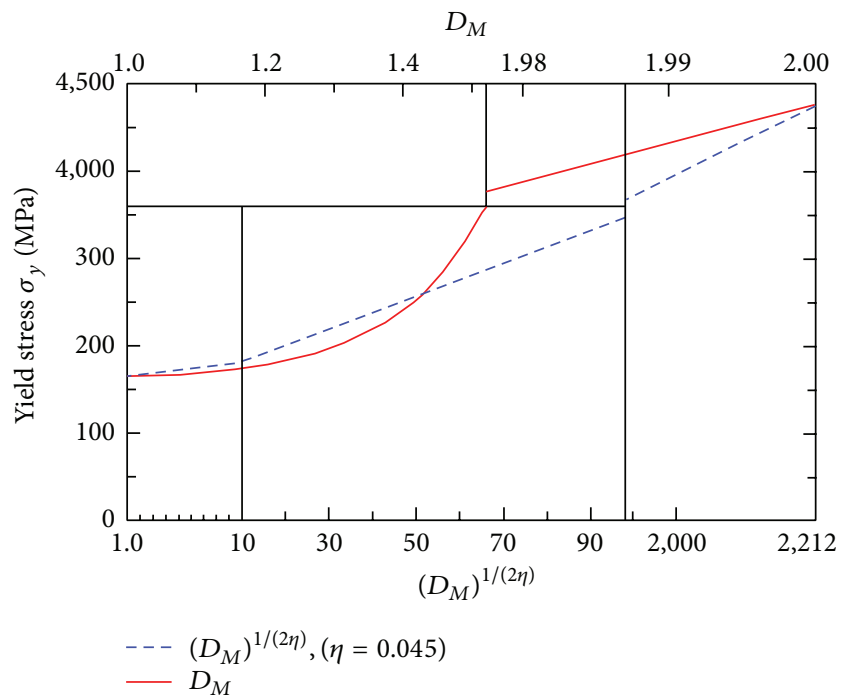

FIGURE 8: Hall-Petch type relations between yield stress and microstructural fractal dimension for AISI $316 \mathrm{~L}$ austenitic stainless steel.

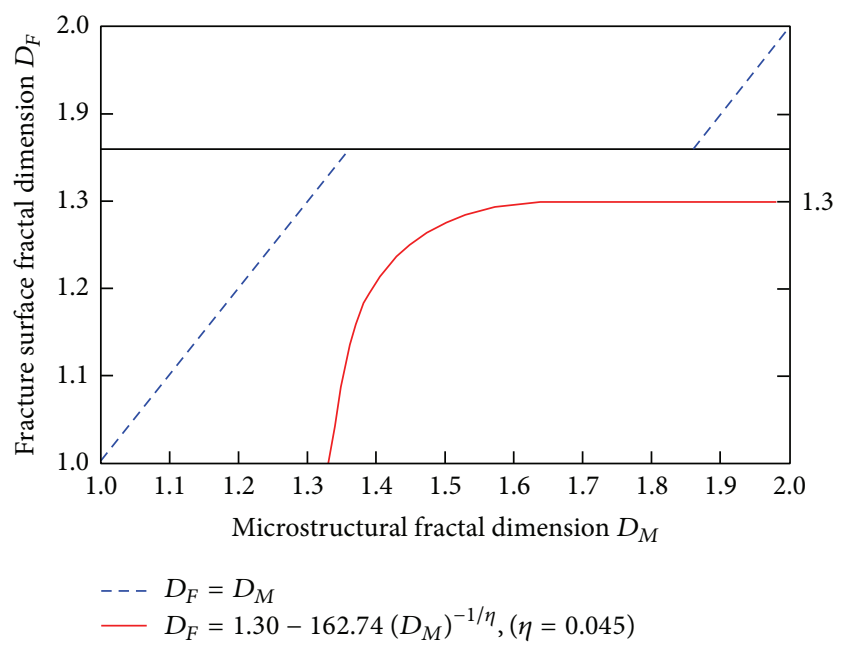

Figure 9: Microstructural fractal dimension $D_{M}$ versus fracture surface fractal dimension $D_{F}$ as compared with $D_{F}=D_{M}$.

has been used by Colás [36] to determine $D_{M}$, and the slitisland method $[17,19,24,38,39,41]$, used in the present work to determine $D_{F}$, are based on 2D metallographic image obtained by grinding the specimen surface flat, the kind of microstructures in which they were applied is essentially different. Note that the different methods to determine $D_{F}$ are, in theory, equivalent, but the SIM method was selected because it is more suitable for the analysis of a rough surface. In addition, a great part of the $D_{F}$ data in the literature is based on this method, which facilitates comparison. In spite of the above, the changes in $D_{F}$ and $D_{M}$ for the corresponding range of grain sizes were the same: $\Delta D_{F}=(1.281)-(1.142)=$ 0.139 and $\Delta D_{M}=(1.504)-(1.365)=0.139$ (Tables 1 and 2). Although these results can be regarded as fortuitous, they suggest, in principle, that the increase in complexity 
experienced by the net of grains between $1194^{\circ} \mathrm{C}$ and $904^{\circ} \mathrm{C}$ (increasing the value of $D_{M}$ ) was completely translated into the respective fracture surface. No previous results for the correlation between $D_{M}$ and $D_{F}$ exist for AISI 316L stainless steel, which makes a comparison difficult to achieve.

Estimating the influence of the microstructural fractal dimension on the fracture surface fractal dimension can be very important, theoretically and in practical applications. The connection between fractal characteristics of materials and mechanical properties can be easily established through equations such as (4) and (6).

\section{Conclusions}

From the present study, it can be seen that the fracture surface fractal dimension $D_{F}$ and the fractal dimension of the grain microstructure $D_{M}$ in AISI $316 \mathrm{~L}$ austenitic stainless steel can be related to the strength of the material through the Hall-Petch law, which provides a well-established and sound platform to study and analyze this relation. The present results indicate the strong interplay between micrograins (microstructure), yield stress (mechanical property), and fracture topography (fracture behavior) for the studied material. The increase in complexity of the microstructure as the grain size decreases is measured by $D_{M}$ and translated into the fracture surfaces, which become more irregular as indicated by the values of $D_{F}$. The relation between grain size, $D_{M}$, mechanical properties, and $D_{F}$, developed for AISI 316L steel, should be generalized and applied to most of the commercial metallic alloys of technological importance.

\section{Conflict of Interests}

The authors declare that there is no conflict of interests regarding the publication of this paper.

\section{Acknowledgments}

The authors would like to thank the staff of the Electron Microscopy Center of the Faculty of Science of the Central University of Venezuela for their assistance, the Ferrum C.A. for providing test material, and the Scientific and Humanistic Development Council of the Central University of Venezuela for financial support.

\section{References}

[1] G. Cao and Y. Wang, Nanostructures and Nanomaterials: Synthesis, Properties and Applications, World Scientific Publishing, Singapore, 2011.

[2] H. Conrad and J. Narayan, "Mechanisms governing the plastic deformation of nanocrystalline materials, including grain-size softening," in Mechanical Properties of Nanocrystalline Materials, J. C. M. Li, Ed., Pan Stanford Publishing, Danvers, Mass, USA, 2011.

[3] H. K. D. H. Bhadeshia, "The first bulk nanostructured metal," Science and Technology of Advanced Materials, vol. 14, no. 1, Article ID 014202, 2013.
[4] T. J. Rupert, "Solid solution strengthening and softening due to collective nanocrystalline deformation physics," Scripta Materialia, vol. 81, pp. 44-47, 2014.

[5] S. Huang, Y.-X. Zhao, and C.-F. He, "Shear fracture of advanced high strength steels," Journal of Iron and Steel Research International, vol. 21, no. 10, pp. 938-944, 2014.

[6] F. Barlat, G. Vincze, J. J. Grácio, M.-G. Lee, E. F. Rauch, and C. N. Tomé, "Enhancements of homogenous anisotropic hardening model and application to mild and dual-phase steels," International Journal of Plasticity, vol. 58, pp. 201-218, 2014.

[7] I. B. Okipnyi, P. O. Maruschak, V. I. Zakiev, and V. S. Mocharskyi, "Fracture mechanism analysis of the heat-resistant steel 15Kh2MFA(II) after laser shok-wave processing," Journal of Failure Analysis and Prevention, vol. 14, no. 5, pp. 668-674, 2014.

[8] J. C. Stinville, J. Cormier, C. Templier, and P. Villechaise, "Modeling of the lattice rotations induced by plasma nitriding of 316L polycrystalline stainless steel," Acta Materialia, vol. 83, pp. 10-16, 2015.

[9] H. Mirzadeh, "Constitutive behaviors of magnesium and Mg$\mathrm{Zn}$-Zr alloy during hot deformation," Materials Chemistry and Physics, vol. 152, pp. 123-126, 2015.

[10] M. Jobba, R. K. Mishra, and M. Niewczas, "Flow stress and work-hardening behaviour of Al-Mg binary alloys," International Journal of Plasticity, vol. 65, pp. 43-60, 2015.

[11] T. Dursun and C. Soutis, "Recent developments in advanced aircraft aluminium alloys," Materials and Design, vol. 56, pp. 862-871, 2014.

[12] M. Harooni, J. Ma, B. Carlson, and R. Kovacevic, “Two-pass laser welding of AZ31B magnesium alloy," Journal of Materials Processing Technology, vol. 216, pp. 114-122, 2014.

[13] B. Chen, S. Cao, H. Xu, Y. Jin, S. Li, and B. Xiao, "Effect of processing parameters on microstructure and mechanical properties of $90 \mathrm{~W}-6 \mathrm{Ni}-4 \mathrm{Mn}$ heavy alloy," International Journal of Refractory Metals and Hard Materials, vol. 48, pp. 293-300, 2015.

[14] A. Srivastava, L. Ponson, S. Osovski, E. Bouchaud, V. Tvergaard, and A. Needleman, "Effect of inclusion density on ductile fracture toughness and roughness," Journal of the Mechanics and Physics of Solids, vol. 63, pp. 62-79, 2014.

[15] R. Bidulský, J. Bidulská, and M. A. Grande, "Correlation between microstructure/fracture surfaces and material properties," Acta Physica Polonica A, vol. 122, no. 3, pp. 548-552, 2012.

[16] M. May, A new approach to discovering the fundamental mechanisms of hydrogen failure [Ph.D. thesis], University of Illinois Urbana-Champaign, Champaign, Ill, USA, 2013.

[17] B. B. Mandelbrot, D. E. Passoja, and A. J. Paullay, "Fractal character of fracture surfaces of metals," Nature, vol. 308, no. 5961, pp. 721-722, 1984.

[18] R. H. Dauskardt, F. Haubensak, and R. O. Ritchie, "On the interpretation of the fractal character of fracture surfaces," Acta Metallurgica et Materialia, vol. 38, no. 2, pp. 143-159, 1990.

[19] V. Y. Milman, N. A. Stelmashenko, and R. Blumenfeld, "Fracture surfaces: a critical review of fractal studies and a novel morphological analysis of scanning tunneling microscopy measurements," Progress in Materials Science, vol. 38, no. 1, pp. 425-474, 1994.

[20] O. A. Hilders, L. Sáenz, M. Ramos, and N. D. Peña, "Effect of $475^{\circ} \mathrm{C}$ embrittlement on fractal behavior and tensile properties 
of a duplex stainless steel," Journal of Materials Engineering and Performance, vol. 8, no. 1, pp. 87-90, 1999.

[21] O. A. Hilders, M. Ramos, N. D. Peña, and L. Sàenz, "Fractal geometry of fracture surfaces of a duplex stainless steel," Journal of Materials Science, vol. 41, no. 17, pp. 5739-5742, 2006.

[22] M. Ostoja-Starzewski and J. Li, "Fractal materials, beams, and fracture mechanics," Zeitschrift für Angewandte Mathematik und Physik, vol. 60, no. 6, pp. 1194-1205, 2009.

[23] W. Tang and Y. Wang, "Fractal characterization of impact fracture surface of steel," Applied Surface Science, vol. 258, no. 10, pp. 4777-4781, 2012.

[24] L. R. Carney and J. J. Mecholsky, "Relationship between fracture toughness and fracture surface fractal dimension in AISI 4340 steel," Materials Sciences and Applications, vol. 4, no. 4, pp. 258267, 2013.

[25] A. Vinogradov, I. S. Yasnikov, and Y. Estrin, "Stochastic dislocation kinetics and fractal structures in deforming metals probed by acoustic emission and surface topography measurements," Journal of Applied Physics, vol. 115, no. 23, Article ID 233506, 2014.

[26] O. A. Hilders and N. Zambrano, "The effect of aging on impact toughness and fracture surface fractal dimension in SAF 2507 super duplex stainless steel," Journal of Microscopy and Ultrastructure, vol. 2, no. 4, pp. 236-244, 2014.

[27] G. G. Savenkov, B. K. Barakhtin, and K. A. Rudometkin, "Multifractal analysis of structural modifications in a cumulative jet," Technical Physics, vol. 60, no. 1, pp. 96-101, 2015.

[28] N. Hirota, F. Yin, T. Azuma, and T. Inoue, "Yield stress of duplex stainless steel specimens estimated using a compound HallPetch equation," Science and Technology of Advanced Materials, vol. 11, no. 2, pp. 1-11, 2010.

[29] N. Stanford, U. Carlson, and M. R. Barnett, "Deformation twinning and the Hall-Petch relation in commercial purity Ti," Metallurgical and Materials Transactions A, vol. 39, no. 4, pp. 934-944, 2008.

[30] H. Izadi, R. Sandstrom, and A. P. Gerlich, "Grain growth behavior and Hall-Petch strengthening in friction stir processed Al 5059," Metallurgical and Materials Transactions A: Physical Metallurgy and Materials Science, vol. 45, no. 12, pp. 5635-5644, 2014.

[31] S. Thangaraju, M. Heilmaier, B. S. Murty, and S. S. Vadlamani, "On the estimation of true Hall-Petch constants and their role on the superposition law exponent in $\mathrm{Al}$ alloys," Advanced Engineering Materials, vol. 14, no. 10, pp. 892-897, 2012.

[32] W. Yuan, S. K. Panigrahi, J.-Q. Su, and R. S. Mishra, "Influence of grain size and texture on Hall-Petch relationship for a magnesium alloy," Scripta Materialia, vol. 65, no. 11, pp. 994997, 2011.

[33] S. Hui, Z. Yugui, and Y. Zhenqi, "Fractal analysis of microstructures and properties in ferrite-martensite steels," Scripta Metallurgica et Materiala, vol. 25, no. 3, pp. 651-654, 1991.

[34] R. W. Armstrong, "Engineering science aspects of the HallPetch relation," Acta Mechanica, vol. 225, no. 4-5, pp. 1013-1028, 2014.

[35] M. A. Tschopp, H. A. Murdoch, L. J. Kecskes, and K. A. Darling, "Bulk' nanocrystalline metals: review of the current state of the art and future opportunities for copper and copper alloys," Journal of the Minerals, Metals \& Materials Society, vol. 66, no. 6, pp. 1000-1019, 2014.
[36] R. Colás, "On the variation of grain size and fractal dimension in an austenitic stainless steel," Materials Characterization, vol. 46 , no. 5, pp. 353-358, 2001.

[37] M. S. Nixon and A. S. Aguado, Feature Extraction \& Image Processing for Computer Vision, Academic Press, London, UK, 2012.

[38] L. V. Meisel, "Perimeter-area analysis, the slit-island method and the fractal characterization of metallic fracture surfaces," Journal of Physics D: Applied Physics, vol. 24, no. 6, pp. 942-952, 1991.

[39] O. A. Hilders and D. Pilo, "On the development of a relation between fractal dimension and impact toughness," Materials Characterization, vol. 38, no. 3, pp. 121-127, 1997.

[40] O. A. Hilders, M. Ramos, N. D. Peña, L. Sáenz, and R. A. Caballero, "Plasticity-fractal-behavior trends for different aluminum alloys tested in tension," in Aluminium Alloys Their Physical and Mechanical Properties, J. F. Nie, A. J. Morton, and B. C. Muddle, Eds., The Institute of Materials Engineering Australasia, Brisbane, Australia, 2004.

[41] P. Mazurek and D. O. Mazurek, "From the slit-island method to the ising model: analysis of irregular grayscale objects," International Journal of Applied Mathematics and Computer Science, vol. 24, no. 1, pp. 49-63, 2014.

[42] J. Feder, Fractals, Plenum Press, New York, NY, USA, 1988.

[43] C. Wang, M. Wang, J. Shi, W. Hui, and H. Dong, "Effect of microstructure refinement on the strength and toughness of low alloy martensitic steel," Journal of Materials Science \& Technology, vol. 23, no. 5, pp. 659-664, 2007.

[44] Z. Fan, "The grain size dependence of ductile fracture toughness of polycrystalline metals and alloys," Materials Science and Engineering A, vol. 191, no. 1-2, pp. 173-183, 1995.

[45] J. M. Li, L. Lü, M. O. Lai, and B. Ralph, Image-Based Fractal Description of Microstructures, Kluwer Academic Publishers, Norwell, Mass, USA, 2003.

[46] Z. Q. Mu and C. W. Lung, "Studies on the fractal dimension and fracture toughness of steel," Journal of Physics D: Applied Physics, vol. 21, no. 5, pp. 848-850, 1988.

[47] D. Shi, J. Jiang, E. Tian, and C. Lung, "Perimeter-area relation and fractal dimension of fracture surfaces," Journal of Materials Science \& Technology, vol. 13, no. 5, pp. 416-420, 1997.

[48] D. Ma, D. Chen, S. Wu, H. Wang, C. Cai, and G. Deng, "Dynamic experimental verification of void coalescence criteria," Materials Science and Engineering A, vol. 533, pp. 96-106, 2012.

[49] W. M. Garrison Jr. and A. L. Wojcieszynski, "A discussion of the spacing of inclusions in the volume and of the spacing of inclusion nucleated voids on fracture surfaces of steels," Materials Science and Engineering A, vol. 505, no. 1-2, pp. 5261, 2009.

[50] C. S. Kusko, J. N. Dupont, and A. R. Marder, "The influence of microstructure on fatigue crack propagation behavior of stainless steel welds," Welding Journal, vol. 83, no. 1, pp. 6-14, 2004.

[51] M. A. Meyers, A. Mishra, and D. J. Benson, "Mechanical properties of nanocrystalline materials," Progress in Materials Science, vol. 51, no. 4, pp. 427-556, 2006.

[52] K. A. Padmanabhan, S. Sripathi, H. Hahn, and H. Gleiter, "Inverse Hall-Petch effect in quasi- and nanocrystalline materials," Materials Letters, vol. 133, pp. 151-154, 2014. 
[53] E. Hornbogen, "Fractals in microstructure of metals," International Materials Reviews, vol. 34, no. 6, pp. 277-296, 1989.

[54] R. J. Mitchell, H. Y. Li, and Z. W. Huang, "On the formation of serrated grain boundaries and fan type structures in an advanced polycrystalline nickel-base superalloy," Journal of Materials Processing Technology, vol. 209, no. 2, pp. 1011-1017, 2009.

[55] K. J. Kim, H. U. Hong, and S. W. Nam, "Investigation on the formation of serrated grain boundaries with grain boundary characteristics in an AISI 316 stainless steel," Journal of Nuclear Materials, vol. 393, no. 2, pp. 249-253, 2009. 

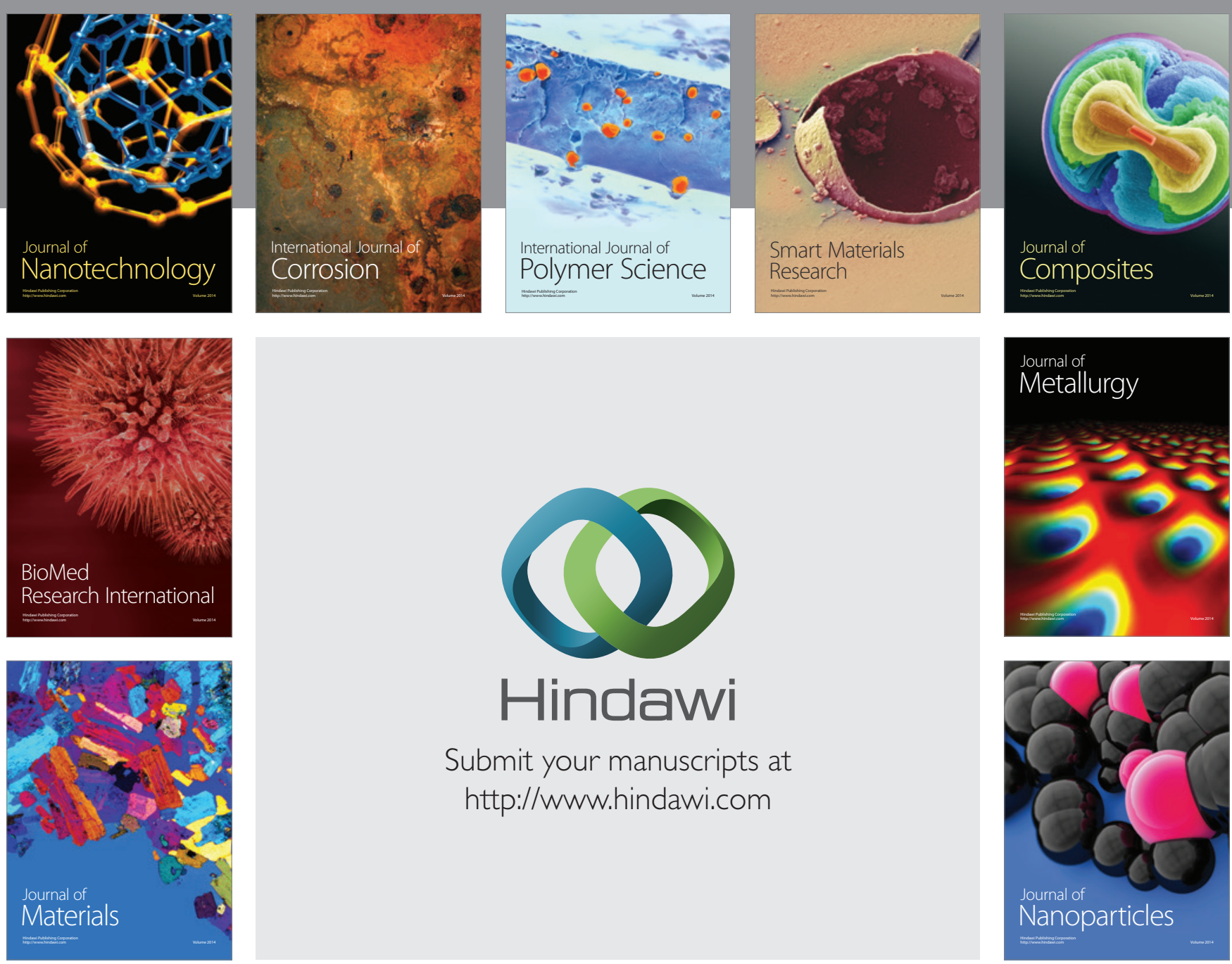

Submit your manuscripts at http://www.hindawi.com
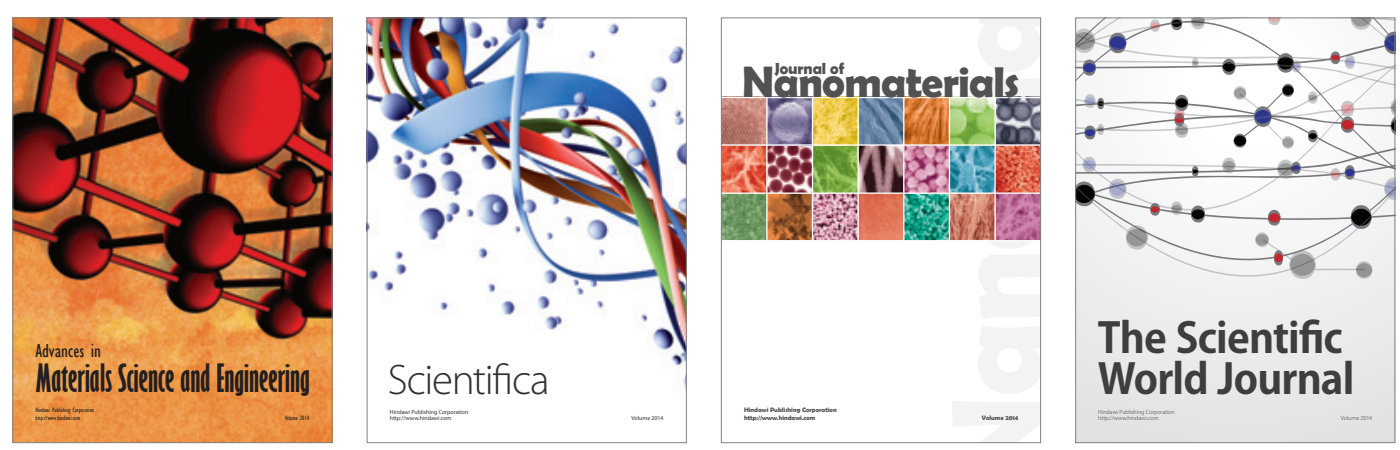

\section{The Scientific World Journal}
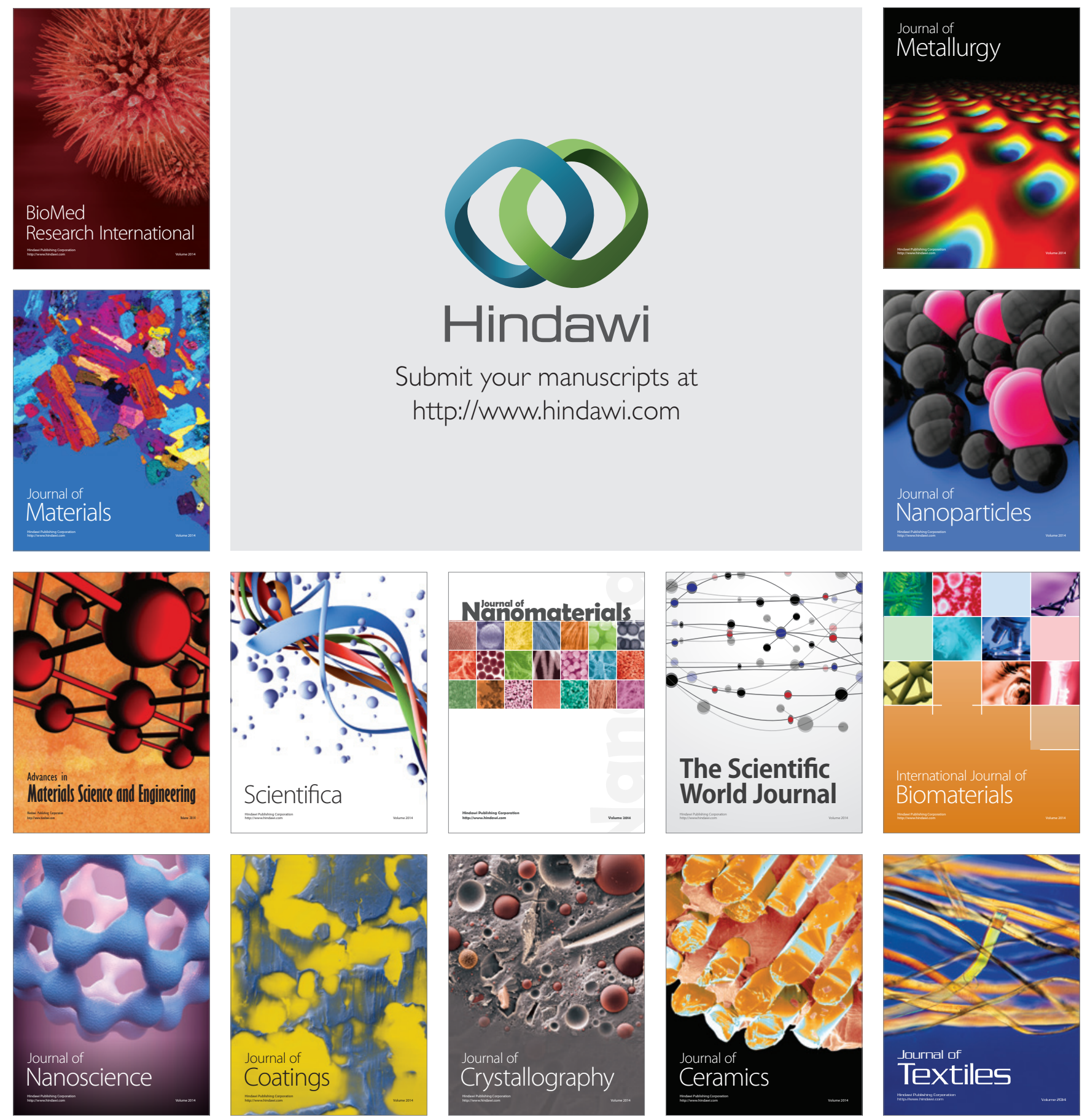